\title{
Das ficções do livro à mão do historiador
}

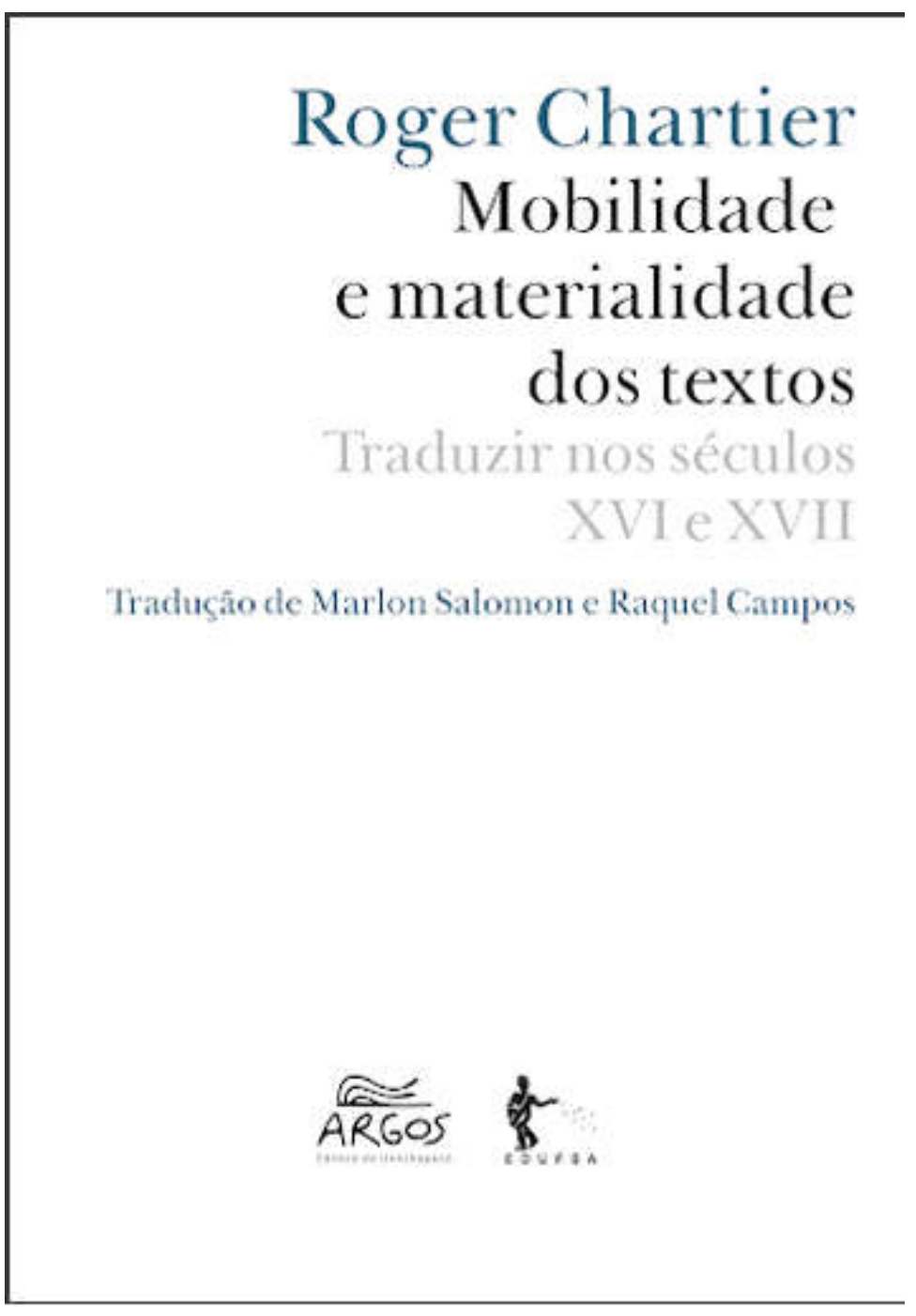

\section{Maicon da Silva Camargo}

Mestre e doutor em História pela Universidade Federal de Goiás (UFG). maiconcamargo.msc@gmail.com 


\section{Das ficções do livro à mão do historiador}

From the book's fictions to the Historian's hand

Maicon da Silva Camargo

CHARTIER, Roger. Mobilidade e materialidade dos textos: traduzir nos séculos XVI e XVII. Tradução de Marlon Salomon e Raquel Campos. Chapecó-Salvador: Argos/Edufba, 2020, 209 p.

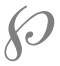

No rastro de práticas que se manifestaram já no século XIX, com a revolução historiográfica dos Annales as obras literárias se tornaram objeto de análise dos historiadores. A partir daí, um problema latente, mas não comumente apresentado como tal, colocou-se: qual a contribuição da disciplina histórica às análises literárias? A recente publicação do consagrado historiador Roger Chartier, Mobilidade e materialidade dos textos: traduzir nos séculos XVI e XVII, embora não trate da questão que levantamos, produz tanto reflexões que nos permitem compreender tal problemática quanto, por sua própria prática historiográfica, corrobora para ilustrar um modo de historicizar obras literárias e livros em geral.

Esse lançamento é a reunião de quatro ensaios de Roger Chartier sobre o "século de ouro" da Espanha (séc. XVII) e a movimentação dos textos no tempo, no espaço e nos sentidos. Dessa maneira, contrariando a ideia de autoridade e sacralidade do autor inventada pelo romantismo e idealismo alemão, essa obra exemplifica "a cadeia de intervenções que conferem formas e sentidos às obras", revelando a interseção da materialidade do texto com os inúmeros atores que contribuem para a produção de um livro (autores, escribas, censores, tradutores, editores, impressores, livreiros, corretores, tipógrafos) e a constituição de sentido do texto (p. 7). O trabalho de Chartier demonstra que as interpretações de um escrito relacionam-se peculiarmente com sua própria materialidade e historicidade.

O primeiro ensaio, "Publicar: as setes vidas da Brevíssima relacíon de la destruycíon de las Índias", coloca em cena a obra clássica de Bartolomeu de las Casas. Nesse estudo, Chartier identifica sete diferentes regimes de sentido que o texto lascasiano foi adquirindo ao longo das suas distintas edições e traduções em três séculos:1) um texto que denunciava as violências e crueldades dos conquistadores espanhóis na América contra os povos indígenas, bem como uma defesa do apostolado de Las Casas; 2) as traduções protestantes utilizaram da obra como propaganda contra a Espanha nas províncias dos Países Baixos ansiosas pela separação política com a Espanha católica; 3) a primeira edição com imagens foi publicada e se insere na guerra de imagens entre católicos e protestantes no interior dos conflitos religiosos da moderni- 
dade; 4) os catalães fizeram uso do livro em sua guerra contra Felipe IV, pensando eles mesmos e os indígenas como vítimas do império castelhano; 5) a obra circulou no mundo inglês como apologia a Cromwell, como apelo para minimizar os conflitos entre os ingleses, convocando-os a se unirem contra o inimigo comum, os espanhóis, e também como um esforço de legitimar o direito da Inglaterra sobre as Índias Ocidentais; 6) ainda no universo inglês, ela transformou-se em um repositório de denúncias de um relato de viagem em que Las Casas foi concebido como um percursor da Revolução Gloriosa, e 7) as múltiplas reedições do texto espanhol nas décadas de 1810 e 1820 foram produzidas pelas colônias espanholas contra a metrópole.

Estas últimas retrataram Las Casas como um santo e profeta das revoluções americanas. Paradoxalmente, o tratado de Las Casas, que escancarava as crueldades dos conquistadores e dos encomenderos, tornou-se uma arma poderosa nas mãos dos criollos, os descendentes dos espanhóis na América, em seu combate pela independência das colônias. Chartier, por historicizar esse documento fundamental para a história da América, complexifica questões caras para nós levando-nos a repensar algumas leituras decoloniais como, por exemplo, as considerações de Enrique Dussel acerca de Las Casas e do que ele denominou de "antidiscurso filosófico" - uma crítica ao pensamento e à filosofia europeia cujo fundador seria o próprio Las Casas. ${ }^{1}$

O segundo estudo, "Representar: Fuente Ovejuna", analisa uma comedia de Lope de Vega, publicada em 1619, que dramatizou a revolta de 1476 dos habitantes da villa de Fuente Ovejuna, na Andaluzia, contra seu senhor Fernán Gómez de Guzmán, tal como o acontecimento foi narrado na crônica de Francisco de Rades y Andrada, trazida a público em 1572. Chartier percorreu os caminhos do texto: do acontecimento histórico à sua narrativa em crônica; desta à comédia encenada por Vega; e dos manuscritos preparados para a encenação às edições para a publicação.

Através de Vega, que possuía uma relação ambígua com os impressos, Chartier analisa várias problemáticas em torno das impressões modernas. E nos ajuda a compreender questões como a noção de autoria, problematizada por Foucault. ${ }^{2}$ Além disso, a análise ilustra a diligência que os historiadores devem ter ao buscarem a realidade histórica por intermédio da representação poética. Neste caso, por exemplo, foram "as necessidades da representação e as expectativas do público" que guiaram "sua composição, muito mais do que o respeito pelas regras aristotélicas" (p. 74), de modo que a construção da narrativa produz todo um conflito que é "dramático e não histórico" (p. 106), conforme podemos observar nos paralelos traçados entre a crônica e a comedia por Chartier.

No terceiro ensaio, "Traduzir: do Oráculo manual a L'homme de Cour [O cortesão], Chartier mostra como a tradução de uma obra pode engendrar uma outra, constituindo sentidos nunca antes imaginados pelo autor. O Oráculo manual y arte de prudência (1647), de Baltasar Gracián, era destinado a todos para auxiliar no cultivo da prudência, virtude cardeal, a fim de que as pessoas

${ }^{1}$ DUSSEL, Enrique. Meditações anticartesianas sobre a origem do antidiscurso filosófico da modernidade. In: SANTOS, Boaventura de Sousa e MENESES, Maria Paula (orgs.). Epistemologias do Sul. São Paulo: Cortez, 2010.

2 Ver FOUCAULT, Michel. O que é um autor? Lisboa: Veja/Passagens, 1992. 
pudessem viver melhor em um mundo, segundo o autor, corrompido e pecador.

Já na tradução francesa, de 1684, feita por Amelot de La Houssaie, este optou por traduzir o título para L'homme de Cour [O cortesão], afirmando em seu prefácio que as máximas do livro seriam muito uteis à vida civil e à vida da Corte, espaços onde a prudência fazia-se mais necessária. Assim, o livro se tornou uma espécie de "Rudimento de Corte e de código político" (p. 130). Por sinal, na mensagem "Ao leitor" da obra em espanhol, havia uma oposição estabelecida entre o leitor digno daquela matéria e o plebeyo cualquier [o vulgo]. Amelot traduziu plebeyo por "menor burguês", instituindo, por essa via, uma oposição entre a Corte e a cidade, o burguês e o gentil-homem, algo inexistente no escrito original.

Constatam-se, por fim, mudanças radicais na tradução de alguns aforismos, alterando o sentido deles. Por exemplo, no lugar em que aparecia a tensão entre perder o juízo e o necessário autoconhecimento que possibilitaria não perder o juízo, a tradução de Amelot acabou por criar a ideia de que se impunha ao homem da Corte possuir autocontrole para dissimular suas intenções e as dos outros. Tudo isso é muito relevante, até porque a importante análise de Norbert Elias sobre o processo civilizador tem nessa obra de Gracián um de seus documentos fundamentais. ${ }^{3}$ Elias, aliás, considera o autocontrole como elemento imprescindível da sociedade de Corte e do processo civilizatório. Todavia, repetimos, no livro original não se trata da vida na Corte; mais, a palavra Corte nem mesmo é mencionada nele. Elias consultou a tradução francesa, citando Amelot acreditando citar Gracián. ${ }^{4}$

Por último, o quarto ensaio, "Adaptar: Dom Quixote e as marionetes de Lisboa", concentra-se na adaptação da obra de D. Quixote para o teatro em Vida do grande Dom Quixote de la Mancha e do gordo Sancho Pança. Trata-se de uma peça de marionetes apresentada no Teatro do Bairro Alto de Lisboa, em 1733, por Antônio José da Silva, um cristão-novo nascido no Rio de Janeiro em 1705. Para Chartier, tal estudo deve levar em conta três histórias ou temporalidades próprias: a das adaptações teatrais da segunda parte da novela de cavalaria D. Quixote, a do teatro de marionetes e "a história de um dramaturgo três vezes confrontado à Inquisição e à dolorosa condição dos 'conversos'”' (p. 192). Além dos problemas inerentes à adaptação de um romance de cavalaria para um teatro de marionetes, Chartier aponta um problema complexo à história da literatura e às relações entre história, literatura e crítica literária: as relações entre vida do autor e obra.

\footnotetext{
${ }^{3}$ Ver ELIAS, Norbert. O processo civilizacional (v. 1). Lisboa: Dom Quixote, 1989; idem, O processo civilizador (v. 2). Rio de Janeiro: Zahar, 1993, e idem, A sociedade de Corte. Rio de Janeiro: Jorge Zahar, 2001.

${ }^{4}$ A propósito, no prefácio da edição de 1985 de A sociedade de Corte, de Norbert Elias [edição brasileira de 2001], Chartier afirmou que era paradoxal convidar um historiador para prefaciar uma obra em que Elias, desde o começo, apresenta "uma crítica radical do procedimento histórico". CHARTIER, Roger. Formação social e economia psíquica: a sociedade de Corte no processo civilizador. In: ELIAS, Norbert. A sociedade de Corte..., op. cit., p. 7. Entretanto, Elias estava criticando certo modelo historiográfico e, por meio de sua sociologia histórica, lançou mão de um método que influenciou muitos historiadores, inclusive o próprio Chartier. Contudo, a necessidade de historicizar um texto, suas condições materiais e não somente seu conteúdo e contexto, conduziu a erro o sociólogo. Daí a importância de todos os que trabalham com textos e livros conhecerem a história do livro, como objeto da cultura, em sua materialidade, a história da leitura, os processos de publicação e tradução de uma obra, temáticas caras a Chartier, às quais ele vem se dedicando no decorrer da sua carreira.
} 
Mobilidade e materialidade dos textos coloca o livro no centro das discussões. O livro não como veículo neutro da transmissão de pensamentos, mas um corpo material que dá forma ao pensamento, agindo e modificando o pensamento que nele se corporifica, bem como agindo e modificando práticas sociais e culturais. Desse modo, diversas práticas entendidas como indiferentes aos processos de significação dos textos merecem, na ótica de Chartier, atenção especial. Editar, imprimir, publicar, traduzir, adaptar, reescrever não são apenas atividades mecânicas e menores no processo de construção de sentido dos textos, e sim agentes e coparticipantes - juntamente com os autores e os processos de leitura - do fenômeno de significação textual.

Nessa linha, no esforço de valorizar atividades por vezes ignoradas pelos leitores, tais como o ato de traduzir, é digno de nota o trabalho de tradução empreendido por Marlon Salomon e Raquel Campos. Não é simplesmente a tradução de uma edição francesa, mas a tradução direta dos escritos de Chartier para um livro inédito do autor publicado primeiramente em língua portuguesa, fato que por si só indica a relevância da recepção desse historiador no Brasil. Ainda mais: graças a esta tradução, os leitores brasileiros poderão acompanhar ainda a remissão das notas de rodapé a textos tanto no original quanto a passagens e eventuais referências contidas em obras editadas em nossa língua.

Enfim, o livro de Chartier ilustra bem diversas teorias das quais muitos estudiosos que trabalham com textos possuem consciência, porém acabam se desviando delas ao tentar aplicá-las. Ele é exemplar por esclarecer como conciliar as várias concepções, metodologias e teorias que o autor desenvolve na esteira de seu trabalho e do tratamento dispensado às "fontes". Aqui, Chartier investiga a constituição do cânone literário, a noção de autoria dos séculos passados, os processos de publicação e constituição de sentido de um texto, respeitando os contextos linguísticos, culturais, sociais e tipográficos, do que resulta uma verdadeira análise arqueológica da publicação de um escrito.

Antoine Lilti ${ }^{5}$ faz uma significativa reflexão a partir do estudo do historiador Lucien Febvre acerca de Rabelais, um autor de ficções da Idade Moderna: o livro, como produto cultural, é sempre a somatória de uma multiplicidade temporal. Cada tempo confere um sentido para determinado texto, que, ao chegar ao público, é uma somatória de múltiplos sentidos que foram se acumulando. Chartier, cujas análises partem desse princípio que é também resultado de uma fina consciência de tempo e de história, aponta, de modo ainda mais palpável e concreto, como a própria materialidade de um livro, seus paratextos e os processos de edição, tradução e publicação reforçam e engendram sentidos.

Assim, por meio dos estudos presentes em Mobilidade e materialidade dos textos percebemos que o livro não é a encarnação eterna do pensamento de um autor. Muito mais do que a identidade entre obra e ideias de um autor, ele reúne em si a multiplicidade de tempos, espaços e agentes produtores de sentidos e todos, eles, diferentes formas, deixam suas marcas numa obra. Disso decorre que, a rigor, analisar um texto comporta, inevitavelmente, um traba-

${ }^{5}$ LILTI, Antoine. Seria Rabelais nosso contemporâneo? História intelectual e hermenêutica crítica. In: SALOMON, Marlon (org.). Heterocronias: estudos sobre a multiplicidade dos tempos históricos. Goiânia: Ricochete, 2018. 
lho arqueológico de escavar distintas camadas de sentido que cada época e cada publicação depositam nesse objeto que contém em si uma tensão semelhante à do homem entre a infinitude das ideias/espírito e a finitude de um corpo físico.

Por tudo isso, como se não bastasse sua grande contribuição do ponto de vista teórico e metodológico, Chartier é um dos raros historiadores contemporâneos que conseguem desenvolver com maestria a ciência histórica sem, contudo, abandonar a arte de narrar. Ler Chartier é envolvente. Nos seus estudos, acompanhamos tramas e aventuras protagonizadas por livros, não apenas o pensamento de um autor, um espírito sem corpo, mas o livro mesmo em toda sua materialidade, de tal modo que, embora se trate da história de um objeto, este, pela maneira desse historiador pensar a história, ganha vida e torna-se um sujeito da história.

Resenha recebida em 15 de junho de 2021. Aprovada em 31 de julho de 2021. 